\title{
Is the Household Microwave Recommended to Obtain Antioxidant-Rich Extracts from Lycium barbarum Leaves?
}

\author{
Luna Pollini ${ }^{1,+(D)}$, Federica Ianni ${ }^{1,+}+(\mathbb{D})$, Giuseppa Verducci ${ }^{1}$, Francesca Blasi ${ }^{1, *}$ and Lina Cossignani $^{1,2}(\mathbb{D}$ \\ 1 Department of Pharmaceutical Sciences, Section of Food Science and Nutrition, University of Perugia, \\ via San Costanzo, 06126 Perugia, Italy; luna.pollini@studenti.unipg.it (L.P.); federica.ianni@unipg.it (F.I.); \\ giuseppa.verducci@unipg.it (G.V.); lina.cossignani@unipg.it (L.C.) \\ 2 Center for Perinatal and Reproductive Medicine, University of Perugia, Santa Maria della Misericordia \\ University Hospital, Sant'Andrea delle Fratte, 06132 Perugia, Italy \\ * Correspondence: francesca.blasi@unipg.it; Tel.: +39-075-585-7954 \\ + Both authors contributed equally to this work.
}

Citation: Pollini, L.; Ianni, F.;

Verducci, G.; Blasi, F.; Cossignani, L.

Is the Household Microwave

Recommended to Obtain

Antioxidant-Rich Extracts from

Lycium barbarum Leaves?. Processes

2021, 9, 656. https://doi.org/

$10.3390 /$ pr9040656

Academic Editor: Dariusz Dziki

Received: 21 March 2021

Accepted: 3 April 2021

Published: 9 April 2021

Publisher's Note: MDPI stays neutral with regard to jurisdictional claims in published maps and institutional affiliations.

Copyright: (c) 2021 by the authors. Licensee MDPI, Basel, Switzerland. This article is an open access article distributed under the terms and conditions of the Creative Commons Attribution (CC BY) license (https:/ / creativecommons.org/licenses/by/ $4.0 /)$.
Abstract: Nowadays, much interest is devoted to the extraction of plant materials, considering also their waste and by-products, to obtain antioxidant-rich products. The effect of household microwave-assisted extraction (MAE) on the phenolic content and antioxidant activity of Lycium barbarum leaf extracts was investigated. An experimental design approach was adopted considering solid/liquid ratio (1, 3, and $5 \mathrm{~g}$ of leaves in $150 \mathrm{~mL}$ water), irradiation time (1, 3, and $5 \mathrm{~min}$ ), and microwave power $(300,400$, and $500 \mathrm{~W})$ as independent variables. These three factors and their interactions were studied to evaluate the effect of MAE conditions on the responses of total phenolic content, antioxidant activity, and chlorogenic acid content. The results showed that the analytical parameters were positively influenced by the solid/liquid ratio and time. On the contrary, microwave power was inversely correlated with the investigated responses. This research revealed that microwave extraction conditions should be carefully monitored to obtain bioactive-rich aqueous extracts with high antioxidant activity. A comparison with household traditional methods showed an unexpected lower phenolic content and antioxidant activity for MAE extract in respect to the decoction and infusion. In fact, it was found that L. barbarum leaf infusion had the best functional properties, regarding the investigated characteristics. The outcome of this study has implications for raising awareness that household preparation conditions strongly affect the health properties of herbal extracts.

Keywords: Lycium barbarum leaves; aqueous infusion; chlorogenic acid; optimization; microwaveassisted extraction

\section{Introduction}

Functional herbal-based beverages, the most consumed drink category in the world, play an important role in daily life and contribute to nutritional well-being. The daily use of functional food can be considered a complementary approach for the prevention of some systemic diseases. Their daily intake has been associated with health benefits due to the presence of important bioactive molecules such as vitamins, minerals, and phenols [1]. Moreover, nowadays there is a great deal of interest in the use and preparation of plant-based aqueous beverages using waste and by-products, interesting sources of bioactives. As an example, numerous papers report on leaf infusions [2,3] and decoctions [4,5]. Lycium spp. leaves are interesting wastes of the goji berry production for their traditional use as herbal drugs and the actual potentiality as functional tea and dietary supplements [6]. In fact, even if Lycium leaves are less studied in respect to most used berries [7,8], some authors reported valuable biological activities, including antioxidant, antimicrobial, enzyme inhibitory, and antinflammatory activities [9-13]. These activities were 
associated with the presence of numerous bioactive compounds, including lipopolysaccharides and phenolic compounds, mainly represented by flavonols and phenolic acids. It was reported that chlorogenic acid (CA) was the main phenolic acid in Lycium leaves in alcoholic and hydroalcoholic extracts [9,11,12].

Extraction is the first essential process for obtaining herbal-based products [14]. Recently, in the food and nutraceutical industries, new techniques have been developed and applied in the extraction of various phytochemicals $[15,16]$. For example, supercritical fluid extraction, ultrasound, and microwave-assisted extraction (MAE) are replacing the conventional extraction techniques (i.e., maceration and Soxhlet).

Regarding functional herbal-based beverages, to the best of our knowledge, no study was carried out on the use of Lycium leaves to prepare a drink with potential health properties. For the first time, the effect of household MAE on the antioxidant properties and CA content of $L$. barbarum leaf extracts was investigated. The objectives of the present study are (i) to investigate, using experimental design, the effect of MAE extraction conditions on phenolic content and antioxidant properties of L. barbarum leaf extracts; (ii) to make a comparison with traditional home beverages (decoction and infusion).

\section{Materials and Methods}

\subsection{Materials}

L. barbarum dried leaves were collected in 2019 in Umbria (Perugia, Italy). Diammonium 2,2'-azino bis(3-ethylbenzothiazoline-6-sulphonate) (ABTS; $\geq 98 \%$ ), Folin-Ciocalteu's phenol reagent, gallic acid (97.5-102.5\%), ( \pm )-6-hydroxy-2,5,7,8-tetramethylchromane-2carboxylic acid (Trolox; 97\%), and chlorogenic acid (CA; $\geq 95 \%$ ) were purchased from Sigma-Aldrich (Milan, Italy). High Performance Liquid Chromatography (HPLC) grade, acetonitrile, formic acid, and ultrapure water, were from Carlo Erba (Milan, Italy).

\subsection{Household Microwave Extraction of L. barbarum Leaves}

\subsubsection{Sample Treatment}

The extractions were carried out in a household microwave oven (1350 W max power; $2450 \mathrm{MHz}$ frequency; Samsung-G633C, London, UK). Dried whole L. barbarum leaves were placed in $150 \mathrm{~mL}$ room-temperature oligomineral water (fixed residue: $276 \mathrm{mg} / \mathrm{L}$ ) in a $300 \mathrm{~mL}$ glass backer and located in the oven in different conditions, reported in the following section (Section 2.2.2). Then, the aqueous extracts were placed on ice to cool to room temperature, and filtered through paper filters (MN 615, Macherey-Nagel, Düren, Germany). Finally, the final volume was checked and, if evaporation occurred, water was added to have the same initial volume $(150 \mathrm{~mL})$. The filtered samples were collected in an amber glass bottle and promptly subjected to analysis.

\subsubsection{Experimental Design}

An experimental design software (UMETRICS, Umeå, Sweden), named Statistical Design Package MODDE 5.0 $0^{\mathrm{TM}}$, was employed to evaluate the influence of three independent microwave parameters (solid/liquid ratio, time, microwave power) on the phenolic content and antioxidant activity of MAE extracts from L. barbarum leaves. Table 1 shows the considered factors affecting the extraction efficiency; the independent variables were ratio $\left(\mathrm{X}_{1}\right)$, time $\left(\mathrm{X}_{2}\right)$, and microwave power $\left(\mathrm{X}_{3}\right)$.

Table 1. Independent variables, unit and values of experimental design.

\begin{tabular}{ccc}
\hline Independent Variables & Unit & Values \\
\hline Ratio $\left(X_{1}\right)^{1}$ & $\mathrm{~g} / 150 \mathrm{~mL}$ & $1 ; 3 ; 5$ \\
Time $\left(X_{2}\right)$ & Min & $1 ; 3 ; 5$ \\
Microwave Power $\left(X_{3}\right)$ & Watt & $1 ; 3 ; 5$ \\
\hline${ }^{1}$ Solid/liquid ratio, i.e., dry leaves/water, expressed as leaf weight in grams of dry matter/liquid volume \\
$(\mathrm{g} \mathrm{DM} / \mathrm{mL})$.
\end{tabular}


As dependent variables, the following responses were selected:

- $\quad$ Total phenolic content (TPC), reported as milligrams of gallic acid equivalent per gram of dry matter (mg GAE/g DM);

- $\quad$ Free radical-scavenging activity by ABTS assay, reported as milligrams of Trolox equivalents per gram of dry matter (mg TE/g DM);

- $\quad$ Ferric reducing antioxidant power (FRAP) assay, reported as micromoles of $\mathrm{Fe}^{+2}$ per gram of dry matter $\left(\mu \mathrm{mol} \mathrm{Fe} \mathrm{F}^{+2} / \mathrm{g} \mathrm{DM}\right)$;

- CA content, reported as micrograms per gram of dry matter ( $\mu \mathrm{g} / \mathrm{g} \mathrm{DM})$.

A total of 15 experiments, including three replicated center points, were obtained setting the screening objective and a D-optimal design. Table 2 shows the worksheet with the experimental conditions of the extractions, which were carried out in random order. Multiple linear regression analysis was used to fit the model.

Table 2. Worksheet and responses of the experimental design.

\begin{tabular}{cccc}
\hline Experimental Number & Ratio & Time & Power \\
\hline 1 & 1 & 1 & 300 \\
2 & 5 & 1 & 300 \\
3 & 1 & 3 & 300 \\
4 & 1 & 5 & 300 \\
5 & 3 & 5 & 300 \\
6 & 5 & 5 & 300 \\
7 & 3 & 3 & 400 \\
8 & 1 & 5 & 400 \\
9 & 1 & 1 & 500 \\
10 & 5 & 1 & 500 \\
11 & 1 & 5 & 500 \\
12 & 5 & 5 & 500 \\
13 & 5 & 5 & 500 \\
14 & 5 & 5 & 500 \\
& 5 & 5 & 500 \\
\hline
\end{tabular}

\subsection{Infusion and Decoction Preparations}

The infusion and decoction were obtained by using $2 \mathrm{~g}$ of L. barbarum dried whole leaves (corresponding to the weight of herbal material in a teabag) and $150 \mathrm{~mL}$ of room temperature oligomineral water (corresponding to the volume of a tea cup) in a $300 \mathrm{~mL}$ glass backer.

The infusion was prepared by adding the herbal material in boiling water and allowing it to repose for $5 \mathrm{~min}$. The decoction was prepared by adding cold water on herbal material and boiling for $5 \mathrm{~min}$.

Both infusion and decoction herbal beverages were placed on ice to cool to room temperature and filtered through paper filters. Finally, the final volume was checked and, if evaporation occurred, water was added up to the initial volume $(150 \mathrm{~mL})$. The filtered samples were collected in an amber glass bottle and promptly subjected to analysis.

\subsection{Determination of Total Phenolic Content (TPC)}

The TPC was determined according to the spectrophotometric method reported by Pagano et al. (2017) [17]. The assay involved the reduction of Folin and Ciocalteu's reagent, and the absorbance was measured at $765 \mathrm{~nm}$. The TPC was reported as $\mathrm{mg}$ GAE/g DM. 


\subsection{In Vitro Antioxidant Activities}

\subsubsection{ABTS Assay}

ABTS assay was carried out following the procedure described by Rocchetti et al. (2020) [18]. Sample was added to $\mathrm{ABTS}^{+\cdot}$ reagent and, after $10 \mathrm{~min}$, the absorbance was measured at $734 \mathrm{~nm}$. The antioxidant capacity of each sample was reported as $\mathrm{mg}$ TE/g DM.

\subsubsection{FRAP Assay}

The reducing capacity of the extracts was determined using the FRAP assay [19]. The sample was added to FRAP reagent and, after $30 \mathrm{~min}$, the absorbance was measured at $593 \mathrm{~nm}$. The calibration curve was obtained using aqueous solutions of known $\mathrm{Fe}^{+2}$ concentrations (2-5 Mm). The reducing capacity was expressed as $\mu \mathrm{mol} \mathrm{Fe} \mathrm{F}^{+2} / \mathrm{g} \mathrm{DM}$.

\subsection{HPLC-DAD Analysis of Phenolic Compounds}

The HPLC analysis of leaf extracts was carried out according to a previous paper [9]. A pump Thermo Spectraseries, a diode array detector Spectra System UV6000LP (Thermo Separation Products, Waltham, MA, USA), and a Hypersil GOLD column ( $3 \mu \mathrm{m}$, $150 \times 4.6 \mathrm{~mm}$ ) were used. The mobile phase consisted of $0.1 \%(v / v)$ formic acid in water (A) and $0.1 \%(v / v)$ formic acid in acetonitrile (B), with the following gradient: phase B increased from $5 \%$ to $20 \%$ in $30 \mathrm{~min}$, and then to $95 \%$ in $5 \mathrm{~min}$. The flow rate was $1.0 \mathrm{~mL} / \mathrm{min}$. Xcalibur software version 1.2 (Finnigan Corporation 1998-2000, San Jose, CA, USA) was used for chromatogram and data acquisition.

\subsection{Statistical Analysis}

All the analytical procedures were carried out in triplicate, and the results were expressed as mean \pm standard deviation on dry leaves. Microsoft Excel 2016 (Microsoft Corporation, Redmond, WA, USA) was used for data analysis.

One-way ANOVA (Analysis of Variance) was used to assess the differences among the means of the investigated groups performing the post-hoc Tukey's HSD (Honest Significant Difference) methodology (with a confidence level of 95\%). The statistical analyses were performed using Originpro 2021 software (OriginLab Corporation, Northampton, MA, USA).

\section{Results and Discussion}

\subsection{MAE Extraction of L. barbarum Leaves}

Nowadays, microwave ovens are ubiquitous in homes and workplaces because irradiation is a time-saving and energy-efficient cooking method, useful to prepare herbal beverages. In the present study, the optimization of the conditions of household microwave extraction on some bioactive properties of L. barbarum leaf extracts was studied.

Table 2 shows the worksheet with the extraction conditions of the experiments, designed around a mathematical model with the highest G-efficiency using the software MODDE $^{\mathrm{TM}}$ (MKS Umetrics, Umeå, Sweden). Among the considered responses, in addition to TPC, two complementary antioxidant assays were used: ABTS to evaluate the radical scavenging ability of the MAE extracts and FRAP to evaluate their reducing capacity. CA was chosen because, on the basis of previous results $[9,11,20]$, it was the main phenolic acid detected in L. barbarum leaf extracts. Table 3 shows the experimental values obtained for TPC, FRAP, ABTS, and CA. In order to estimate the coefficients of the terms in the model, representing the relationship between the response $(Y)$ and the factors $\left(\mathrm{X}_{1}, \mathrm{X}_{2}, \ldots\right)$, multiple linear regression analysis was used. 
Table 3. Experimental values of TPC, ABTS, FRAP, and CA of MAE extracts.

\begin{tabular}{ccccc}
\hline Experimental Number & TPC & ABTS & FRAP & CA \\
\hline & mg GAE/g & mg TE/g & $\mu \mathbf{m o l ~ F e}^{\mathbf{+ 2}} \mathbf{g}$ & $\boldsymbol{\mu g} / \mathbf{g}$ \\
\hline 1 & 3.4 & 8.4 & 34.7 & 1.5 \\
2 & 4.4 & 8.4 & 43.3 & 13.2 \\
3 & 4.8 & 12.4 & 57.7 & 7.5 \\
4 & 5.0 & 13.2 & 61.4 & 43.5 \\
5 & 6.2 & 16.3 & 71.9 & 72.0 \\
6 & 5.5 & 11.9 & 60.4 & 195.3 \\
7 & 5.9 & 13.5 & 69.0 & 7.0 \\
8 & 5.3 & 13.9 & 62.5 & 48.0 \\
9 & 2.8 & 9.5 & 29.2 & 1.5 \\
10 & 4.6 & 16.1 & 43.3 & 0.3 \\
11 & 5.7 & 13.0 & 63.0 & 6.0 \\
12 & 5.9 & 11.3 & 72.6 & 144.9 \\
13 & 5.5 & 11.4 & 66.5 & 130.5 \\
14 & 5.8 & 8.3 & 64.4 & 120.0 \\
15 & 5.8 & 10.9 & 73.3 & 115.8 \\
\hline
\end{tabular}

TPC, total phenolic content; ABTS, diammonium 2,2'-azino-bis(3-ethylbenzothiazoline-6-sulphonate); FRAP, ferric reducing antioxidant power; $\mathrm{CA}$, chlorogenic acid; GAE, gallic acid equivalents; TE, Trolox equivalents. The values are expressed as dry weight.

The factor interactions were entered for a better comprehensive understanding of the factor dynamics. In the following, the obtained Equations (1)-(4) for TPC, ABTS, FRAP, and CA are shown:

$$
\begin{gathered}
\mathrm{TPC}=4.81127+0.385671 \mathrm{X}_{1}+0.864694 \mathrm{X}_{2}-0.0420571 \mathrm{X}_{3}-0.267204 \mathrm{X}_{1} \mathrm{X}_{2}+0.0510864 \mathrm{X}_{1} \mathrm{X}_{3} \\
\mathrm{ABTS}=13.5331+2.1559 \mathrm{X}_{1}-1.00171 \mathrm{X}_{2}-0.17909 \mathrm{X}_{3}-3.15727 \mathrm{X}_{1} \mathrm{X}_{2}-0.15509 \mathrm{X}_{1} \mathrm{X}_{3} \\
\mathrm{FRAP}=53.3367+3.17606 \mathrm{X}_{1}+13.1511 \mathrm{X}_{2}-0.61149 \mathrm{X}_{3}-1.87349 \mathrm{X}_{1} \mathrm{X}_{2}+2.14145 \mathrm{X}_{1} \mathrm{X}_{3} \\
\mathrm{CA}=424.573+326.841 \mathrm{X}_{1}+436.109 \mathrm{X}_{2}-114.033 \mathrm{X}_{3}-177292.127 \mathrm{X}_{1} \mathrm{X}_{2}-690.515 \mathrm{X}_{1} \mathrm{X}_{3}
\end{gathered}
$$

The best summary of fit of the model is given by the R2 and Q2 values (Figure 1).

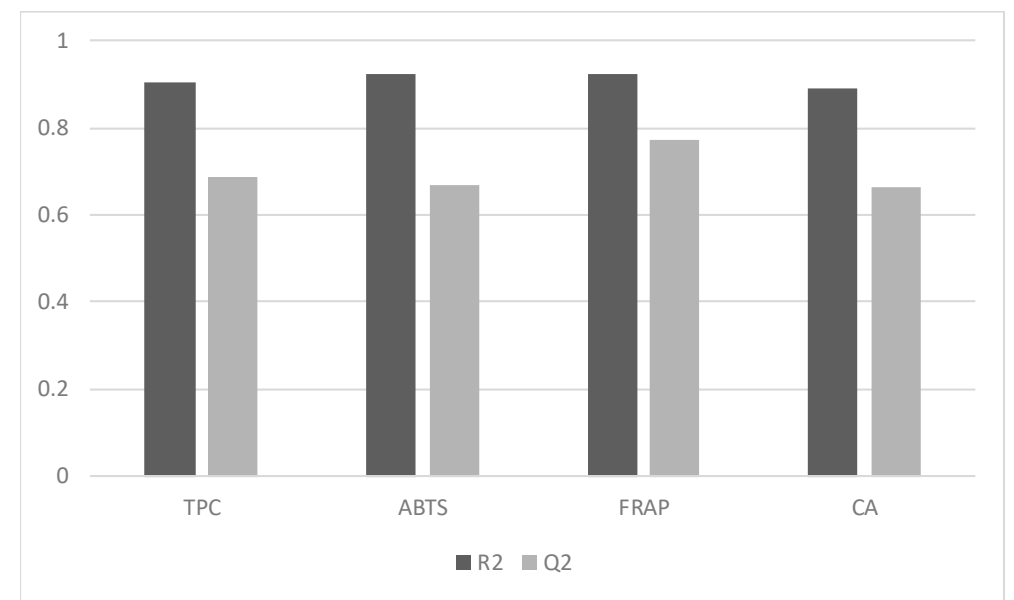

Figure 1. Statistic of the model-R2 and Q2 values of the four responses (TPC, total phenolic content; ABTS, diammonium 2,2'-azino-bis(3-ethylbenzothiazoline-6-sulphonate); FRAP, ferric reducing antioxidant power; $\mathrm{CA}$, chlorogenic acid).

The R2 values ranged from 0.9057 for TPC to 0.9234 for FRAP, meaning that the model fitted the data very closely. The Q2 values ranged between 0.6670 for ABTS and 0.7739 for FRAP, indicating a high predictive accuracy. 
As regards the influence of the different factors, it can be observed from the obtained Equations (1)-(4) that all responses are positively influenced by the $X_{1}$ factor (weight of herbal material $/ 150 \mathrm{~mL}$ of water), while an inverse correlation was found for the $\mathrm{X}_{3}$ factor (microwave power). The $\mathrm{X}_{2}$ factor (time) showed a high positive correlation with TPC, FRAP, and CA. Interesting interactions are represented by ratio $\times$ time (inverse correlations except for $\mathrm{CA}$ ) and $\mathrm{L} / \mathrm{S}$ ratio $\times$ power (positive for TPC and FRAP, negative for ABTS and CA).

As shown in Table 3, the values of the TPC of MAE extracts ranged from $2.8 \mathrm{mg}$ GAE/g (of the sample obtained with ratio 1, irradiation time $1 \mathrm{~min}$, microwave power $500 \mathrm{~W}$ ) to $6.2 \mathrm{mg} \mathrm{GAE} / \mathrm{g}$ of the sample, obtained with a lower microwave power $(300 \mathrm{~W})$, but with a higher ratio (3) and irradiation time (5 min). It was also observed that high irradiation time corresponded to high FRAP value and that TPC values were well correlated to FRAP values $(R 2=0.9192)$. As regards $C A$, the main phenolic acid in L. barbarum leaves, it was observed that its content was higher $(195.3 \mu \mathrm{g} / \mathrm{g} \mathrm{DM})$ when the power of the household microwave was lower (300 Watt), the extraction time was longer $(5 \mathrm{~min})$, and the ratio was higher $(5 \mathrm{~g} / 150 \mathrm{~mL})$. The results obtained for CA confirm those reported for TPC, and it can be deduced that microwave power could lead to the modification of phenolic structure.

Figure 2 shows the surface plots of the responses TPC (a), FRAP (b), and ABTS (c) as a function of time and ratio factors, maintaining the power at $300 \mathrm{Watt}$, and of CA response (d) as a function of ratio and power factors, maintaining the time at $5 \mathrm{~min}$. It is possible to observe that high TPC and FRAP values were relative to a long time, while a short time and high ratio positively influenced ABTS and CA responses.

a

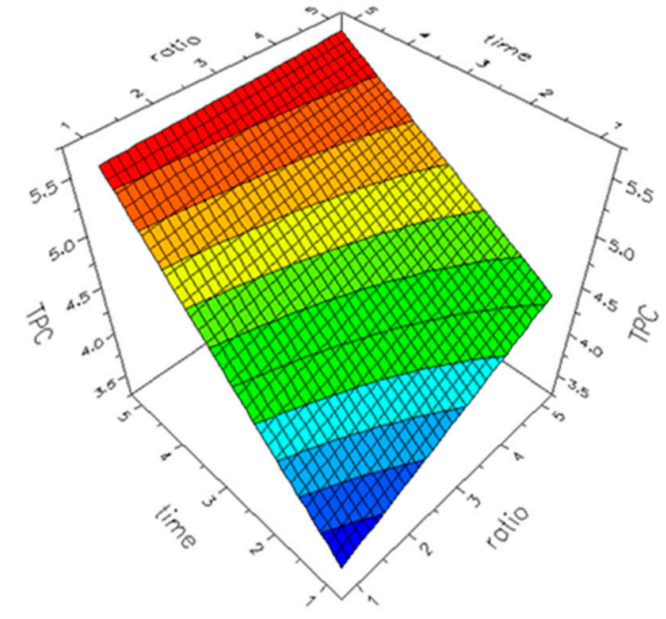

c

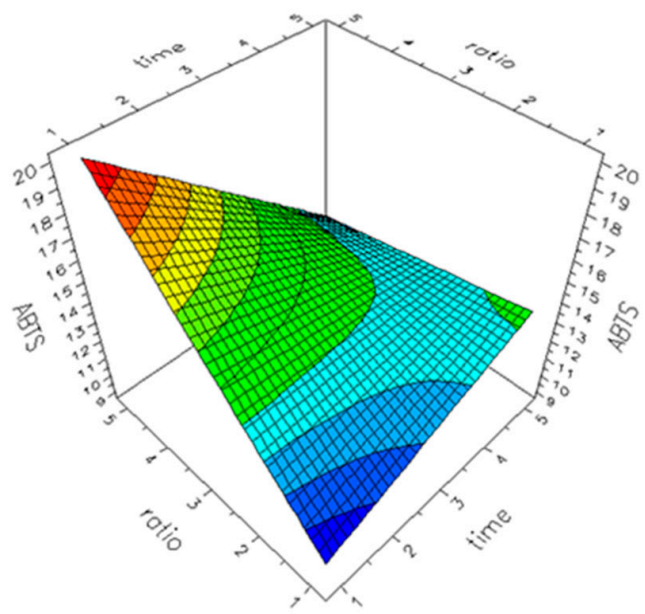

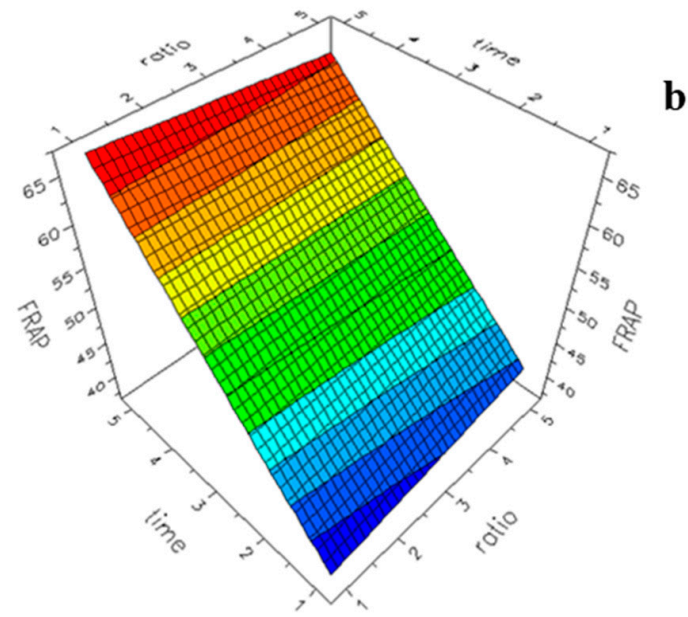

b

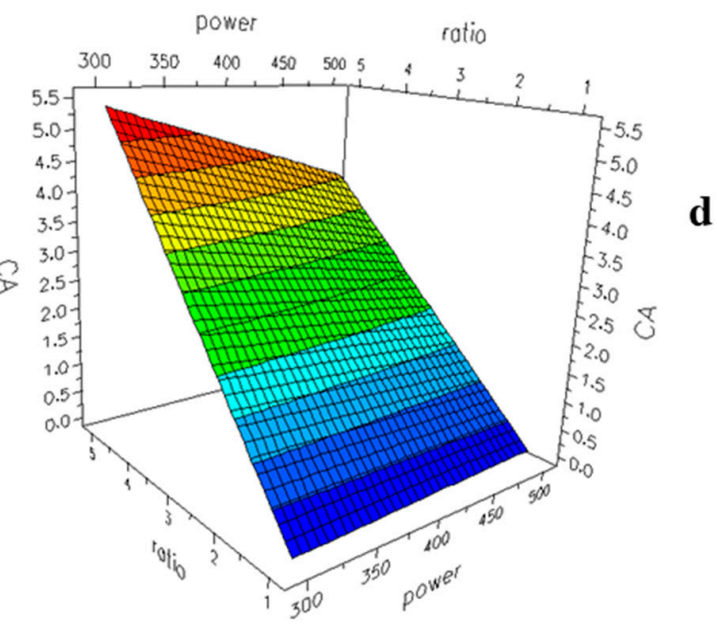

Figure 2. Surface plot showing the responses: (a) TPC (300 Watt), (b) FRAP (300 Watt), (c) ABTS (300 Watt), (d) CA (5 min). 
To make a comparison of the phenolic content and in vitro activities of the MAE extract with classic home preparations, infusions and decoctions were prepared and analyzed. Since two grams of L. barbarum leaves were used to prepare infusions and decoctions $(150 \mathrm{~mL})$, the prediction function of the software provided the values of TPC, FRAP, ABTS, and CA for a MAE extract from two grams of leaves in $150 \mathrm{~mL}$, irradiated for $5 \mathrm{~min}$ at 300 W. Figure 3 shows the values of TPC, FRAP, ABTS, and CA content of L. barbarum leaf extracts obtained by MAE, decoction, and infusion.

The results of post-hoc Tukey's HSD test showed that the difference of the means was significant at the 0.05 level for all the analytical assays among MAE, decoction, and infusion treatments. Unexpectedly, lower values were obtained for the MAE extract compared to both infusion and decoction for all parameters studied; in particular, the CA content was strongly reduced when the MAE treatment was performed. Finally, L. barbarum leaf infusion had the highest values for the analytical assays, thus preserving bioactive compounds of the extract and its related properties.

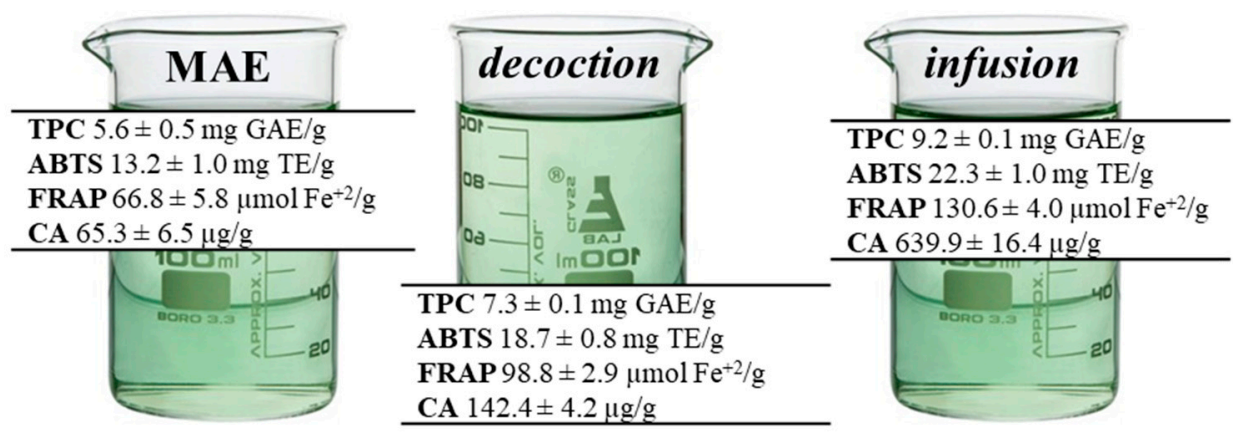

Figure 3. TPC, ABTS, FRAP, and CA content of L. barbarum leaf MAE, decoction, and infusion extracts.

\subsection{Comparison with Literature Data}

In a previous paper, unconventional extraction techniques such as ultrasound-assisted extraction and MAE have been used to extract L. barbarum leaves [9]. The TPC and ABTS values of MAE extracts were similar with the highest values obtained in this paper; however, it should be observed that alcoholic and hydroalcoholic solvents were used. In fact, to the best of our knowledge, this is the first study on household microwave extraction for obtaining $L$. barbarum leaf extract, so it is difficult to make a comparison with the literature data. Other authors studied the microwave assisted extraction of different herbal materials, in particular, green tea leaves [16,21-23]. Taşkın and Özbek have investigated the microwave conditions for the extraction of bioactives from green tea and found that the TPC value increased with an increase in microwave power up to $440 \mathrm{~W}$, while it showed a steady decrease when the power was higher, up to $600 \mathrm{~W}$ [16]. It was concluded that the use of the right combination of some extraction variables (moderate microwave power-long irradiation time) is recommended for obtaining bioactives from waste without thermal deterioration. Vuong et al. (2012) investigated the effect of household microwave on catechins, caffeine, and theanine extraction from commercial teabag [21]. They found that the extracted amounts were lower than those obtained using the manufacturer's instructions (classic decoction), a result similar to what observed in this work. Upadhyay, Ramalakshmi, and Rao (2012) have instead studied the microwave extraction of green coffee bean to obtain chlorogenic acids and reported that the yields of MAE under optimum conditions (water, $800 \mathrm{~W}, 5 \mathrm{~min}$, and $50^{\circ} \mathrm{C}$ ) were higher than those from the conventional aqueous extraction at $5 \mathrm{~min}$ and $50{ }^{\circ} \mathrm{C}$ [23].

Finally, on the basis of the good results obtained in this paper for traditional infusion, a comparison can be made with other plant-based infusions. Among these, Li et al. (2013) studied the properties of 233 medicinal plants, including powdered L. barbarum berries [24] and found similar TPC value to those reported in this paper. Higher TPC values were instead reported for dried goji berry infusions [8]. 


\section{Conclusions}

In this research, for the first time the investigation of MAE parameters on extraction efficiency of bioactives from L. barbarum leaves was carried out. The results showed that ratio and time had a positive influence on the functional properties of leaf extract, while the increase in power corresponded to lower phenolic content and antioxidant properties. The combination of moderate microwave power with long time and high ratio provided higher CA content in MAE extract. Unexpected results were obtained taking into consideration classic household preparations; in fact, the investigated analytical parameters provided lower values for MAE extracts in respect to decoction and infusion. The traditional infusion has proved to be the best procedure for extracting bioactives from L. barbarum leaves and obtaining a functional beverage. Further studies are underway to deepen the knowledge on the effect of microwave extraction on the chemical stability of phenolic compounds in aqueous solutions, with particular regard to the modification of chlorogenic acid due to irradiation power. The control of chemical stability of bioactive compounds from plant materials is mandatory for pilot and large-scale extraction processes.

Author Contributions: Conceptualization, F.B.; methodology, L.P. and F.I.; validation, F.B., formal analysis, L.P. and G.V.; investigation, L.P. and F.I.; writing-original draft, F.I.; writing-review and editing, F.B. and L.C.; supervision, F.B. and L.C.; project administration, L.C.; funding acquisition, L.C. All authors have read and agreed to the published version of the manuscript.

Funding: This work was supported by funding from the University of Perugia: Fondo d'Ateneo per la Ricerca di Base 2018, Project "Caratterizzazione di composti bioattivi estratti da matrici vegetali".

Institutional Review Board Statement: Not applicable.

Informed Consent Statement: Not applicable.

Data Availability Statement: Not applicable.

Conflicts of Interest: The authors declare no conflict of interest.

\section{References}

1. Yilmaz-Akyuz, E.; Ustun-Aytekin, O.; Bayram, B.; Tutar, T. 6-Nutrients, bioactive compounds, and health benefits of functional and medicinal beverages. In Nutrients in Beverages Volume 12: The Science of Beverages; Mihai Grumezescu, A., Holban, A.M., Eds.; Elsevier: Duxford, UK, 2019; pp. 175-235. [CrossRef]

2. Medina, R.; Romero, C.; García, P.; Brenes, M. Characterization of bioactive compounds in commercial olive leaf extracts, and olive leaves and their infusions. Food Funct. 2019, 10, 4716-4724. [CrossRef]

3. Mendonça, G.S.; de Sousa Campos, R.; Gonçalves Abreu, V.K.; de Oliveira Lemos, T.; Fernandes Pereira, A.L. Effect of extract or infusion of leaves of the Hibiscus sabdariffa L. in the production and storage of the beverage blends with cupuassu: Physicochemical and sensory acceptance. J. Food Sci. Technol. 2020. [CrossRef]

4. Khajehei, F.; Niakousari, M.; Damyeh, M.S.; Merkt, N.; Claupein, W.; Graeff-Hoenninger, S. Impact of ohmic-assisted decoction on bioactive components extracted from yacon (Smallanthus sonchifolius Poepp.) leaves: Comparison with conventional decoction. Molecules 2017, 22, 2043. [CrossRef] [PubMed]

5. Adorisio, S.; Fierabracci, A.; Muscari, I.; Liberati, A.M.; Calvitti, M.; Cossignani, L.; Blasi, F.; Quan, T.D.; Tam, N.T.; Van Sung, T.; et al. Artocarpus tonkinensis protects mice against collagen-induced arthritis and decreases Th17 cell function. Front. Pharmacol. 2019, 10, 503. [CrossRef] [PubMed]

6. Conidi, C.; Drioli, E.; Cassano, A. Biologically active compounds from goji (Lycium barbarum L.) leaves aqueous extracts: Purification and concentration by membrane processes. Biomolecules 2020, 10, 935. [CrossRef]

7. Cossignani, L.; Blasi, F.; Simonetti, M.S.; Montesano, D. Fatty acids and phytosterols to discriminate geographic origin of Lycium barbarum berry. Food Anal. Methods 2018, 11, 1180-1188. [CrossRef]

8. Sun, Y.; Rukeya, J.; Tao, W.; Sun, P.; Ye, X. Bioactive compounds and antioxidant activity of wolfberry infusion. Sci. Rep. 2017, 7, 40605. [CrossRef] [PubMed]

9. Pollini, L.; Rocchi, R.; Cossignani, L.; Mañes, J.; Compagnone, D.; Blasi, F. Phenol profiling and nutraceutical potential of Lycium spp. leaf extracts obtained with ultrasound and microwave assisted techniques. Antioxidants 2019, 8, 260. [CrossRef]

10. Lin, S.; AL-Wraikat, M.; Niu, L.; Zhou, F.; Zhang, Y.; Wang, M.; Ren, J.; Fan, J.; Zhang, B.; Wang, L. Degradation enhances the anticoagulant and antiplatelet activities of polysaccharides from Lycium barbarum L. leaves. Int. J. Biol. Macromol. 2019, 133, 674-682. [CrossRef] 
11. Pollini, L.; Riccio, A.; Juan, C.; Tringaniello, C.; Ianni, F.; Blasi, F.; Mañes, J.; Macchiarulo, A.; Cossignani, L. Phenolic acids from Lycium barbarum leaves: In vitro and in silico studies of the inhibitory activity against porcine pancreatic $\alpha$-amylase. Processes 2020, 8, 1388. [CrossRef]

12. Mocan, A.; Vlase, L.; Vodnar, D.C.; Bischin, C.; Hanganu, D.; Gheldiu, A.M.; Oprean, R.; Silaghi-Dumitrescu, R.; Crișan, G. Polyphenolic content, antioxidant and antimicrobial activities of Lycium barbarum L. and Lycium chinense Mill. Leaves. Molecules 2014, 19, 10056-10073. [CrossRef]

13. Bae, S.M.; Kim, J.E.; Bae, E.J.; Kim, K.A.; Ly, S.Y. Anti-inflammatory effects of fruit and leaf extracts of Lycium barbarum in lipopolysaccharide-stimulated RAW264. 7 cells and animal model. J. Nutr. Health 2019, 52, 129-138. [CrossRef]

14. Nazir, M.; Arif, S.; Khan, R.S.; Nazir, W.; Khalid, N.; Maqsoodd, S. Opportunities and challenges for functional and medicinal beverages: Current and future trends. Trends Food Sci. Technol. 2019, 88, 513-526. [CrossRef]

15. Vardanega, R.; Santos, D.T.; Meireles, M.A.A. Intensification of bioactive compounds extraction from medicinal plants using ultrasonic irradiation. Pharmacogn. Rev. 2014, 8, 88-95. [CrossRef] [PubMed]

16. Taşkın, B.; Özbek, Z.A. Optimisation of microwave effect on bioactives contents and colour attributes of aqueous green tea extracts by central composite design. J. Food Meas. Charact. 2020, 14, 2240-2252. [CrossRef]

17. Pagano, C.; Perioli, L.; Blasi, F.; Bastianini, M.; Chiesi, C.; Cossignani, L. Optimisation of phenol extraction from wine using layered double hydroxides and technological evaluation of the bioactive-rich powder. Int. J. Food Sci. Technol. 2017, 52, 2582-2588. [CrossRef]

18. Rocchetti, G.; Pagnossa, J.P.; Blasi, F.; Cossignani, L.; Hilsdorf Piccoli, R.; Zengin, G.; Montesano, D.; Cocconcelli, P.S.; Lucini, L. Phenolic profiling and in vitro bioactivity of Moringa oleifera leaves as affected by different extraction solvents. Food Res. Int. 2020, 127, 108712. [CrossRef] [PubMed]

19. Urbani, E.; Blasi, F.; Simonetti, M.S.; Chiesi, C.; Cossignani, L. Investigation on secondary metabolite content and antioxidant activity of commercial saffron powder. Eur. Food Res. Technol. 2016, 242, 987-993. [CrossRef]

20. Zhao, X.; Guo, S.; Yan, H.; Lu, Y.; Zhang, F.; Qian, D.; Wang, H.; Duan, J. Analysis of phenolic acids and flavonoids in leaves of Lycium barbarum from different habitats by ultra-high-performance liquid chromatography coupled with triple quadrupole tandem mass spectrometry. Biomed. Chromatogr. 2019, 33, e4552. [CrossRef]

21. Vuong, Q.V.; Tan, S.P.; Stathopoulos, C.E.; Roach, P.D. Improved extraction of green tea components from teabags using the microwave oven. J. Food Comp. Anal. 2012, 27, 95-101. [CrossRef]

22. Ghasemzadeh-mohammadi, V.; Zamani, B.; Afsharpour, M.; Mohammadi, A. Extraction of caffeine and catechins using microwave-assisted and ultrasonic extraction from green tea leaves: An optimization study by the IV-optimal design. Food Sci. Technol. 2017, 26, 1281-1290. [CrossRef] [PubMed]

23. Upadhyay, R.; Ramalakshmi, K.; Rao, L.J.M. Microwave assisted extraction of chlorogenic acids from green coffee beans. Food Chem. 2012, 130, 184-188. [CrossRef]

24. Li, S.; Li, S.K.; Gan, R.Y.; Song, F.L.; Kuang, L.; Li, H.B. Antioxidant capacities and total phenolic contents of infusions from 223 medicinal plants. Ind. Crops Prod. 2013, 51, 289-298. [CrossRef] 